\title{
Research on the Influence of Steam Turbine Seal Leakage
}

\author{
Zou Ping-guo ${ }^{1}$, Zhang Zhen-tao ${ }^{1, *}$, and Li Gang ${ }^{1}$ \\ ${ }^{1}$ Suzhou Nuclear Power Research Institute Co.,Ltd, Suzhou, 215004, Jiangsu, China
}

\begin{abstract}
CFD was employed to simulate the steam flow in 1.5-stage cascades with three different seal clearances. When the seal clearance is 0 , there is no steam seal leakage, no obvious secondary flow in the cascade, and the stage efficiency reaches $88.27 \%$. When the clearance of diaphragm seal and rotor tip seal is $1 \mathrm{~mm}$, the leakage of diaphragm seal strongly interferes with the flow in the cascade, which promotes the formation and development of the end-wall secondary flow near rotor hub, and the rotor tip leakage flow has little effect on next stage, and the stage efficiency drops by about 2 percentage points. When the seal clearance is $4 \mathrm{~mm}$, the end-wall secondary flow near rotor hub and next stator casing is strengthened significantly, and the attack angle loss increases, so the stage efficiency decreases by about 13 percentage points.
\end{abstract}

\section{Introduction}

The performance of steam turbine flow path is directly related to the economy and safety of the entire steam turbine unit, and naturally becomes the focus of experimental research, operation optimization and technological transformation. The flow loss in the flowpath of steam turbine cascade is mainly blade profile loss, secondary flow loss and steam leakage loss [1]. Due to the advanced development of aerodynamics and other theories and manufacturing technologies, currently the flow efficiency of steam turbine has reached high level, and the blade profile loss and secondary flow loss have been greatly reduced $[2,3]$, so steam leakage loss has become an important factor restricting the improvement of turbine flow efficiency [4]. Therefore, it is necessary to indepth study the impact of the internal seal leakage on flow performance, which will help site engineers to grasp the working characteristics and status of the steam seal, and guide the optimization or technological innovation of the steam turbine unit.

In the field, the installation location of the internal seals in steam turbine stage is very special. It is very difficult to directly arrange test points on the seal, which makes it impossible to monitor the wear condition of the seal in stage, and it is impossible to judge the influence of the leakage on the flow characteristics in stage. Since it is not easy to directly measure the seal leakage in steam turbine stage [5], this paper chooses to use numerical simulation methods for research.

\section{Numerical simulation of flow field in steam turbine cascade}

\subsection{Geometric model}

The blade profile and seal structure is a 1.5-stage cascade with a diaphragm seal and a rotor tip seal, which are 3 flat tooth labyrinth seal. In order to compare the flow under different seal clearances, the steam flow under three different clearances of 0,1 , and $4 \mathrm{~mm}$ were simulated.

Turbine machinery cascade has periodic flow. In order to improve the efficiency of numerical simulation and analyze the influence of steam leakage on next stage, this paper took a cascade flow-path for research. The simulation object was simplified as a complete stage including diaphragm seal and rotor tip seal, and a stator blade with diaphragm seal. The blades and their seals were referred to as S1, DS1, R1, TS1, S2, DS2. The entire computing domain was divided into 6 areas, namely areas S1, DS1, R1, TS1, S2, and DS2, as shown in Fig.1.

In order to obtain a stable flow field, the front end of the computational domain was appropriately extended. The calculation area used a tetrahedral hybrid grid with strong regional adaptability, and periodic grid on the periodic boundary was adopted.

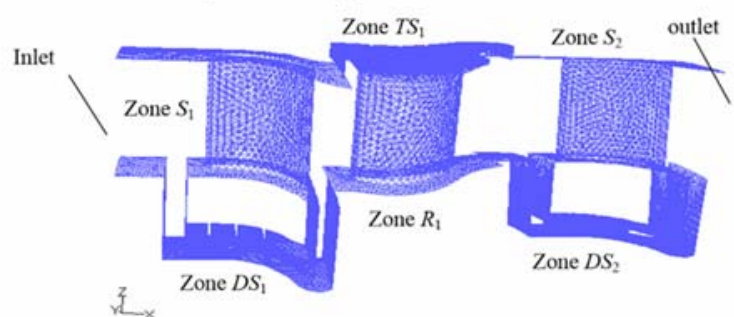

Fig.1 1.5 stage cascade and grid

\footnotetext{
* Corresponding author: zhangzhentao@ecgnpc.com.cn
} 


\subsection{Boundary conditions}

The working fluid was superheated steam. The turbulence model was standard k- $\varepsilon$ two-equation model, and the wall function method was used to deal with the near-wall area. The calculated governing equations were Flow, Turbulence, and Energy. The control equations adopted SIMPLE algorithm of pressure-velocity coupling.

In this example, the total inlet pressure was 3.2MPa, the total temperature $800 \mathrm{~K}$, and the incoming flow direction was perpendicular to the inlet. The static pressure value at the given median diameter of the outlet was $2.6 \mathrm{MPa}$, and a simple radial balance equation was used to determine the pressure distribution on the outlet. The interface parameter transmission between the static and rotor blade areas used multi-reference model (MRF) method. S1, S2, and R1 flow field were given periodic boundary conditions on the circumferential boundary, and internal boundary conditions were given for the contact surface on radial boundary, and wall conditions were given for the rest. The wall rotation speed of R1 area was 3000rpm.

The boundary conditions of the flow field in the sealing area were as follow: given the internal boundary conditions on the contact surface with the blade area, and the circumferential boundary was set as the periodic boundary conditions. Under the condition of constant stage flow rate, the boundary conditions of the inlet and outlet after the change of the seal clearances could be determined according to the Friuli Greig formula.

\section{Comparison and analysis}

\subsection{Comparison of flow field}

\subsubsection{The clearance of seals is 0}
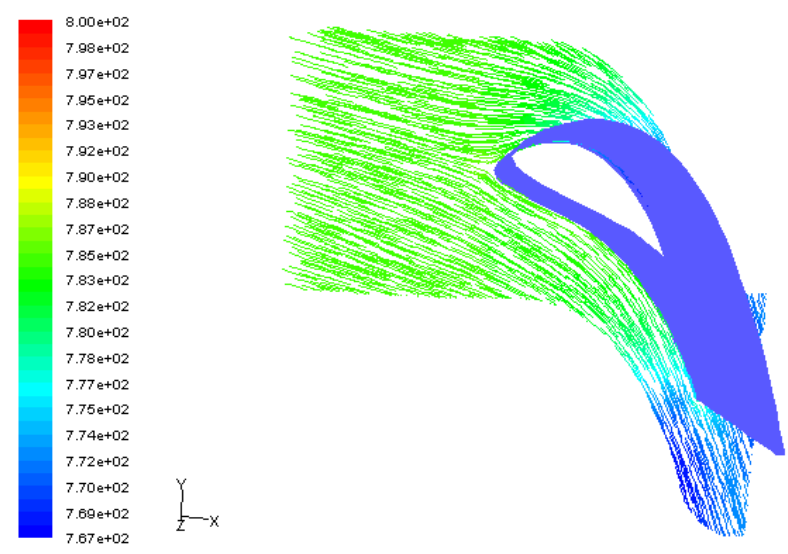

Fig.2 Streamline at bottom of S2 flow-path
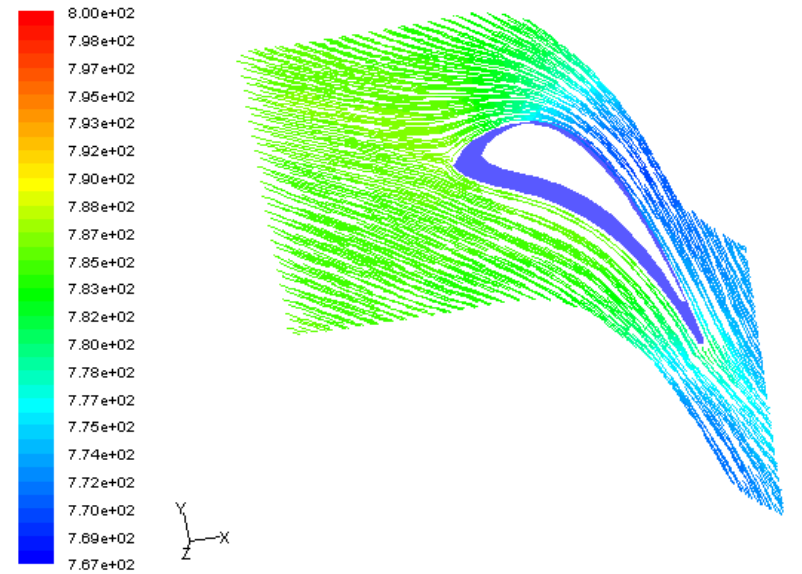

Fig.3 Streamline at top of S2 flow-path

Since there is no steam leakage from seals, the steam can fully expand in stator blade flow-path and perform work in rotor blade flow-path, and the main flow will not be disturbed by leakage. Fig.2 and Fig.3 shows the distribution of streamlines in the flow-path of stator blades S2. It can be seen that the streamlines in S2 flow-path are along the main flow direction, and the flow loss is small. The absolute value of negative attack angle at top of the flow-path further increases, comparing with that at bottom of the flow-path. This is because the circumferential velocity of steam at the leading edge of blade $\mathrm{S} 2$ is larger, and the circumferential speed increases along the leaf height.
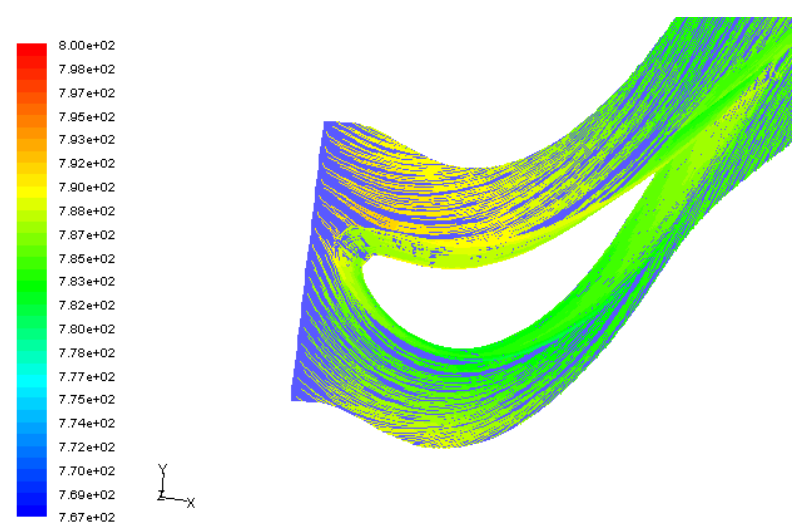

Fig.4 Streamline near R1 hub
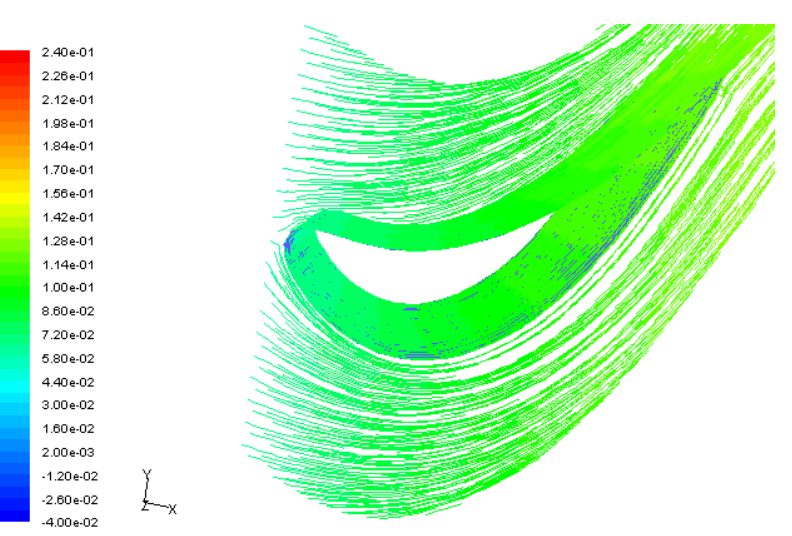

Fig.5 Streamline near R1 casing 

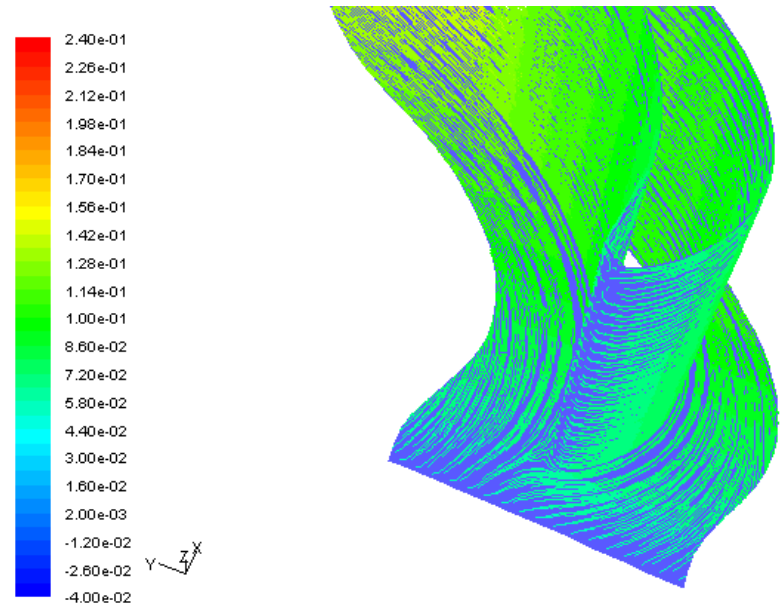

Fig.6 Streamline at R1 leading edge

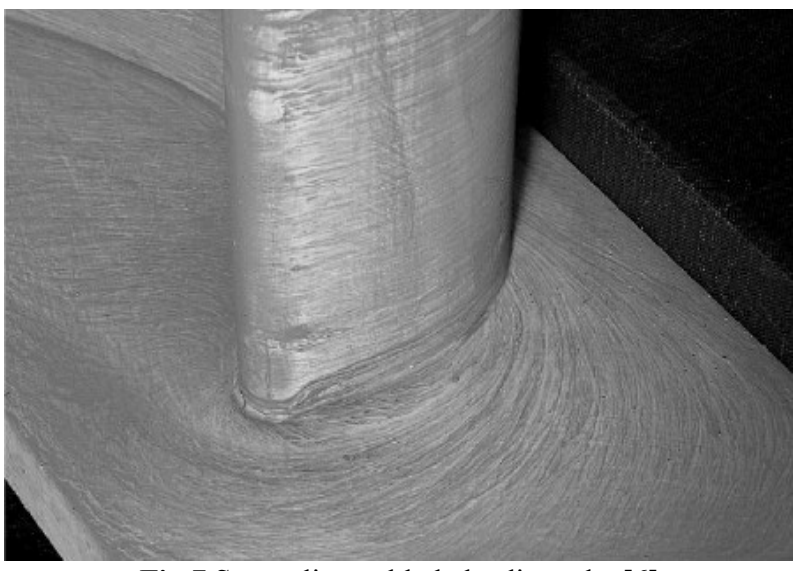

Fig.7 Streamline at blade leading edge[6]

Fig.4 Fig. 7 shows the streamline in the rotor blade flow-path. There is no obvious secondary flow at the endwall of rotor blade $\mathrm{R} 1$, and no passage vortex and lateral secondary flow from the pressure surface to the suction surface are observed. The streamlines regularly flow out of flow-path along the main flow direction. This is because there is no turbulence caused by diaphragm seal leakage, which makes the dimensions of passage vortex, reverse vortex, and corner vortex become very small and difficult to be observed. The streamlines at leading edge of R1 are separated at saddle point. Because there is no strong lateral pressure gradient, the horseshoe vortex on pressure surface has not developed into a strong passage vortex.

\subsubsection{The clearance of seals is $1 \mathrm{~mm}$}
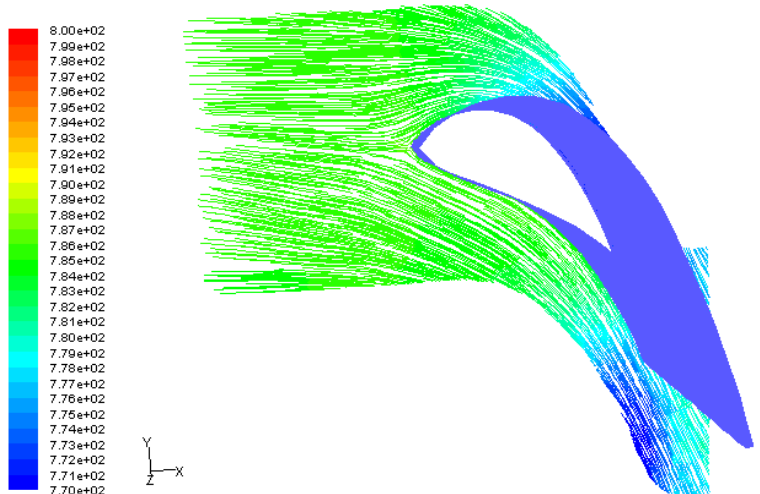

Fig.8 Streamlines at bottom of S2 flow-path
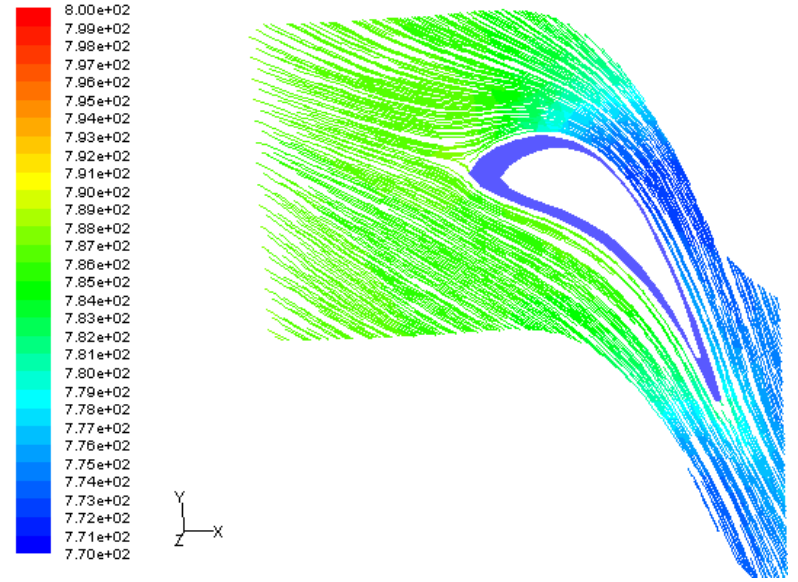

Fig.9 Streamlines at top of S2 flow-path

It can be seen from Fig.8 Fig.9 that saddle points or horseshoe vortex at the leading edge of blade S2. Due to the small size of each vortex, it is difficult to observe the passage vortex, reverse vortex, etc. here. The absolute value of negative attack angle at the inlet increases continuously along the height of S2, and the negative attack angle in the tip area does not cause obvious flow separation on the suction surface. Therefore, the flow condition in stator blade S2 cascade is good, and the streamlines are basically along the main flow direction, and there is no flow separation, which indicates that the blade profile loss and the secondary flow loss in the stator blade are small. There is no significant secondary flow at the top of S2 flow-path, which indicates that the steam leakage of R1 tip seal has little effect on the steam flow in S2 flow-path.
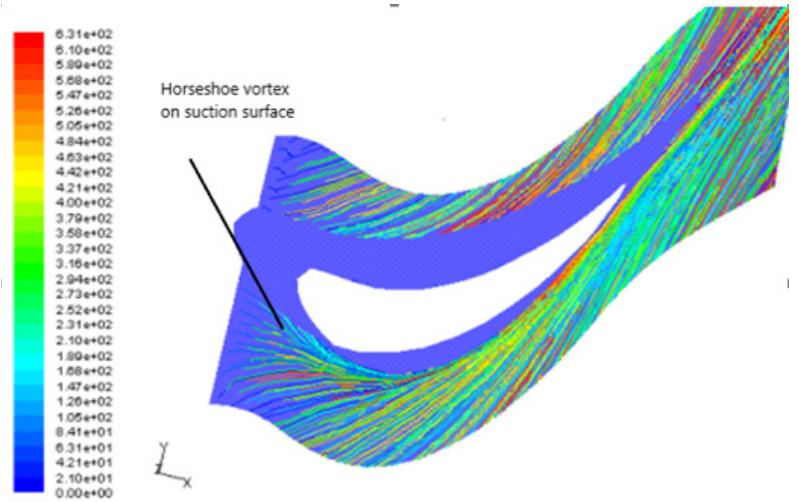

Fig.10 Streamlines near R1 hub with seal clearance of $1 \mathrm{~mm}$

As shown in Fig.10, there is strong secondary flow near R1 hub. The streamlines of the leading edge separate to form two horseshoe vortexes on pressure and suction surface. The horseshoe vortex on pressure surface further evolves into passage vortex. Under the action of the transverse pressure gradient in blade flow-path, passage vortex develops and extends from the leading edge to the suction surface, which causes the boundary layer at the rear of suction surface thicker. So the leakage flow of diaphragm seal DS1 promotes the formation and strengthening of the secondary flow in rotor blade flowpath. The leakage flow has a small circumferential velocity and a large radial velocity. After entering R1 flow-path, it has a significant effect on the steam flow, 
which increases and strengthens the secondary flow area near R1 hub.

\subsubsection{The clearance of seals is $4 \mathrm{~mm}$}
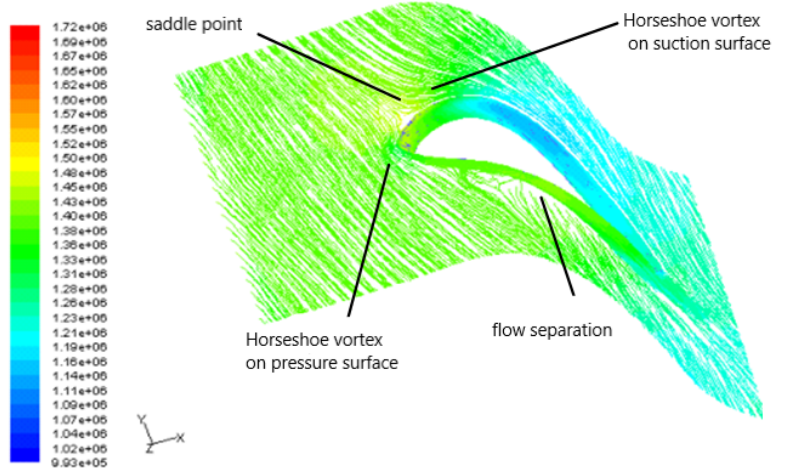

Fig.11 Streamline near S2 casing with seal clearance of $4 \mathrm{~mm}$

The secondary flow near S2 casing is due to a large amount of R1 tip seal leakage flows into S2 flow-path, making the upper flow of S2 flow-path uneven, and at the same time, the incoming flow has a large negative attack angle. After it hits the blade surface, pressure stagnation occurs, forming two horseshoe vortexes on the pressure and suction surfaces. At the same time, it forms a flow separation area on the pressure surface at top of S2 flowpath, and the boundary layer thickens, as shown in Fig.11.
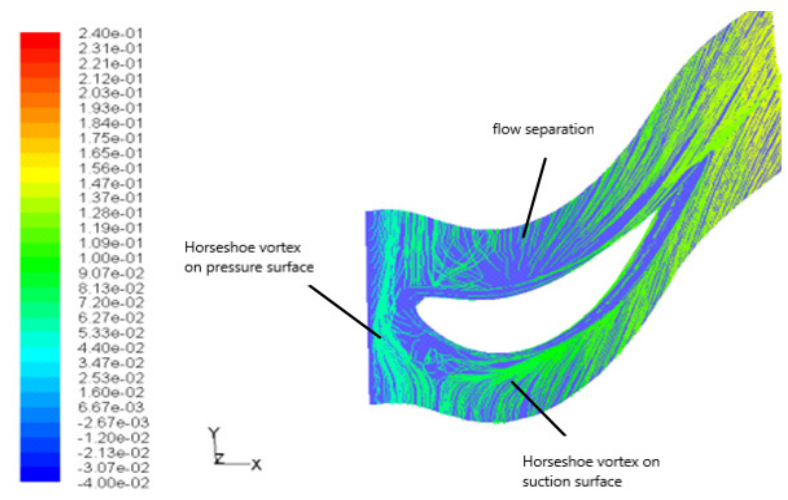

Fig.12 Streamline near R1 hub with seal clearance of $4 \mathrm{~mm}$

As shown in Fig.12, due to the interference of a large amount of diaphragm seal leaks, the absolute value of negative attack angle of R1 is abnormally increased, and the steam inlet angle is close to perpendicular to the axial chord. Under such condition, a large area of localized flow separation occurs on R1 pressure surface. Obvious lateral secondary flow can be seen near the end-wall. The pressure-surface horseshoe vortex flows directly from the leading edge to the suction surface to form a passage vortex, and the suction surface horseshoe vortex develops into a reverse vortex at the root of R1 suction surface.

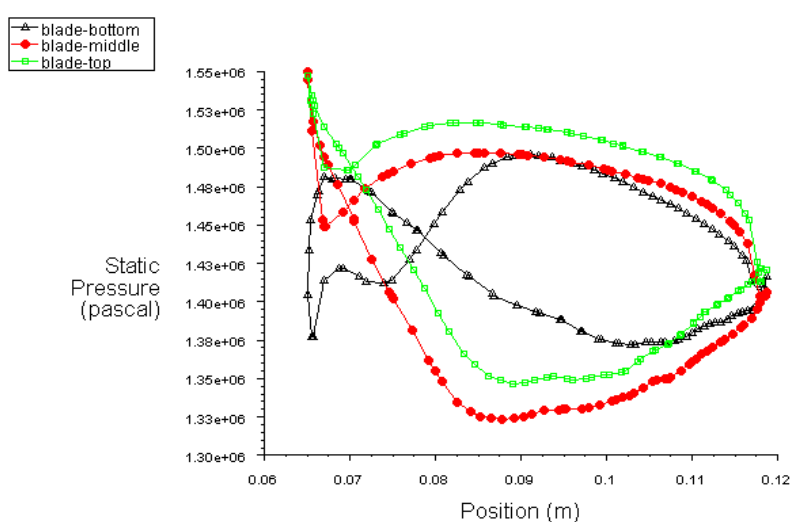

Fig.13 Static pressure distribution of R1 profiles at different $\square$ nozle2-bottom
- - nozzle2-middle

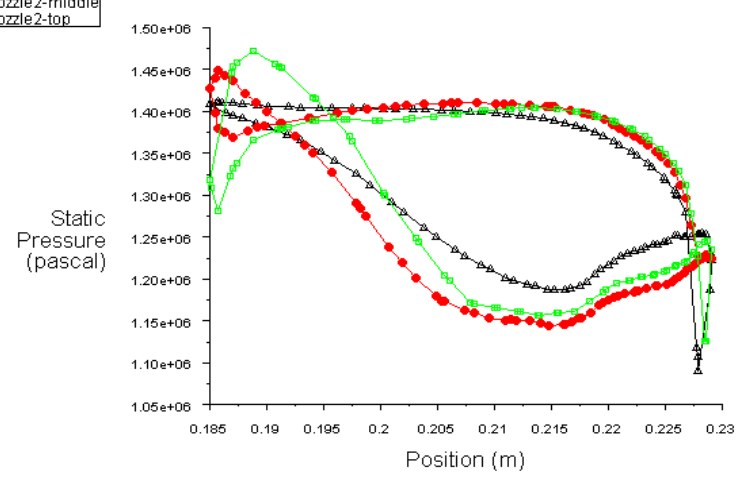

Fig.14 Static pressure distribution of S2 profiles at different height

Fig.13 14 shows the static pressure distribution on the surface of R1 and S2. The over-expansion phenomenon appears at the inlet of R1 pressure surface. This is due to the large negative attack angle of the incoming flow. The absolute value of the negative attack angle decreases along the blade height, and the over-expansion phenomenon is also weakened. The phenomenon of deceleration and pressurization appears at the inlet of S2 suction surface. The pressurization effect is the most significant at the blade tip of suction surface, and no steam overexpansion is observed at the root of suction surface.

\subsection{Comparison of flow efficiency}

Under different seal clearances, the pressure and temperature parameters of inlet and outlet are shown in Table 1.

Table 1. Results of thermal parameters at the main interface

\begin{tabular}{|c|c|c|c|c|c|}
\hline \multirow{2}{*}{$\begin{array}{c}\text { Paramet } \\
\text { er }\end{array}$} & $\begin{array}{c}\text { Seal } \\
\text { clearance } \\
(\mathrm{mm})\end{array}$ & Inlet & $\begin{array}{c}\text { S1 } \\
\text { outlet }\end{array}$ & $\begin{array}{c}\text { R1 } \\
\text { outlet }\end{array}$ & S2outlet \\
\hline \multirow{2}{*}{$\begin{array}{c}\text { Pressure } \\
(\mathrm{MPa})\end{array}$} & 0 & 3.220 & 2.959 & 2.880 & 2.630 \\
\cline { 2 - 6 } & 4 & 3.200 & 2.950 & 2.871 & 2.626 \\
\hline \multirow{2}{*}{$\begin{array}{c}\text { tempera } \\
\text { ture (K) }\end{array}$} & 1 & 3.133 & 2.908 & 2.815 & 2.623 \\
\cline { 2 - 6 } & 4 & 800.00 & 787.95 & 782.71 & 771.62 \\
\cline { 2 - 6 } & 4 & 800.00 & 789.50 & 785.56 & 776.91 \\
\hline
\end{tabular}


When the seal clearance is 0 , the total flow of the cascade is $2.735 \mathrm{~kg} / \mathrm{s}$, the leakage flow of each seal is 0 , and the calculated stage efficiency is $88.27 \%$. When the seal clearance is $1 \mathrm{~mm}$, the total inlet flow is also $2.735 \mathrm{~kg} / \mathrm{s}$, and DS1 leakage flow is $0.049 \mathrm{~kg} / \mathrm{s}$, TS1 leakage flow $0.015 \mathrm{~kg} / \mathrm{s}$, DS 2 leakage flow $0.048 \mathrm{~kg} / \mathrm{s}$, so the relative internal efficiency of the stage is $86.43 \%$. When the seal clearance is $4 \mathrm{~mm}$, the total inlet flow is $2.735 \mathrm{~kg} / \mathrm{s}$, of which DS1 leakage flow is $0.221 \mathrm{~kg} / \mathrm{s}$, TS1 leakage flow is $0.057 \mathrm{~kg} / \mathrm{s}$, DS 2 leakage flow is $0.218 \mathrm{~kg} / \mathrm{s}$, and the relative internal efficiency is $75.79 \%$.

\subsection{Discussion and analysis}

The losses caused by seal leakage mainly include the following. First, the leakage does not expand in stator blade or the leakage bypasses rotor tip seal, and it cannot do work in rotor blade flow-path. Secondly, the high damping leakage flow makes its entropy value much larger than that of the fluid in flow-path, with vortexes. Finally, the leakage enters the cascade and mixes with the mainstream, so irreversibility will inevitably lead to a further increase in the entropy. Studies have shown that the entropy increase loss caused by mixing has the same order of magnitude as the entropy increase of the leakage in seals [2]. It can be seen that the leakage will inevitably cause the reduction of the steam flow in cascade and the increase of flow loss.

In this paper, when the seal clearance is 0 , there is only circumferential flow in seals, and the leakage loss is 0 . The internal losses are mainly blade profile loss and secondary flow loss. Since there is no leakage interference, the streamline in flow-path are basically along the main flow direction, and the secondary flow loss is also small, so the stage efficiency is the highest at this time. When seal clearance is $1 \mathrm{~mm}$, the stage efficiency will drop by about 2 percentage points due to the leakage. If seal clearance is $4 \mathrm{~mm}$, the amount of leakage increases sharply. This part of the leaked steam cannot do work in the stage, and at the same time it interferes with thermal conversion process of the mainstream, resulting in large-scale passage vortex and reverse vortex in flow-path. The negative attack angle of rotor incoming flow and secondary flow near the endwall have increased significantly, and flow separation appears on the suction surface of rotor blade \& stator blade of next stage. A large amount of effective energy consumption is dissipated as heat, and the flow efficiency drops by about 13 percentage points.

\section{Conclusion}

When the seal clearance is 0 , when there is no leakage loss, the secondary flow in the cascade is weak, and the stage efficiency is the highest. In the case that a seal clearance is $1 \mathrm{~mm}$, the diaphragm leakage has a strong interference to the flow in rotor blade flow-path, and while the leakage of rotor tip seal has little effect on next stage, and the stage efficiency drops about 2 percentage points. When the seal clearance is $4 \mathrm{~mm}$, the secondary flow near rotor blade hub and the casing of next stator blade is significantly enhanced, and flow separation occurs on the suction surface of rotor blade, and while the loss of attack angle increases at the inlet of rotor blade and next stator blade. The suction surface of rotor blade and next stator blade has local flow separation, and the stage efficiency drops by about 13 percentage points. In comparison, the effect of the diaphragm seal leakage is greater than that of the rotor tip seal leakage.

\section{References}

1. Cofer J I IV.Advances in Steam Path Technology[J]. ASME Journal of Engineering for Gas Turbines and Power, 1996, 118: 337-352.

2. J.D.Denton. Loss Mechanisms in Turbomachines [J]. Journal of Turbomachinery, OCT.1993, Vol.115, 621656.

3. Clayton M.Grondahl and James C.Dudley. FILM RIDING LEAF SEALS FOR IMPROVED SHAFT SEALING[C]. Proceedings of ASME Turbo Expo 2010:Power for Land, Sea and Air GT2010, Glasgow, UK.

4. PALMER T R,TAN C S,ZUNIGA H,et al.Quantifying loss mechanisms in turbine tip shroud cavity flows[J]. Journal of Turbomachinery. 2016

5. Jie Gao,Qun Zheng. Comparative investigation of unsteady flow interactions in endwall regions of shrouded and unshrouded turbines[J]. Computers and Fluids . 2014

6. David Gregory-Smith, David Bagshaw, Grant Ingram. TUSING PROFILED ENDWALLS, BLADE LEAN AND LEADING EDGE EXTENSIONS TO MINIMISE SECONDARY FLOW [J]. Proceedings of ASME Turbo Expo 2008: Power for Land, Sea and Air GT2008 June 9-13, 2008, Berlin, Germany 